\title{
The Journal in the 1970s
}

The first issue of a new year seems appropriate to review the policy of the Journal as it has been established for nearly a quarter of a century. As in the earliest issues, our policy is still clearly defined as that of publishing all that is best in the four main disciplines of clinical pathology - histology, haematology, bacteriology, and chemical pathology. Naturally, as the years have gone by, we have had minor swings in the proportion of papers submitted and published in each of these four disciplines but, overall, the pattern has remained amazingly constant. In other words, clinical pathologists are still pursuing their work in the laboratories and the consequent research in the traditional fields. Having said that, however, we must point to the most notable innovation in clinical laboratories, and one that has now been applied to all the disciplines. The great newcomer is automation. We have been accused both of publishing too much on automation and recently of neglecting the subject. In fact, we think we have kept the balance admirably. We have published many papers on the application of automation to clinical pathology, and we have also carried studies of the machines themselves.

In histology the new emphasis has been on the use of histochemistry in differentiating and establishing diagnoses, and the electron microscope has opened our eyes more widely. We have published various histological studies based on the use of the electron microscope and, with their accompanying electronmicrographs, these have been most valuable and visually beautiful.

In this number we are introducing a new section called 'Present-day Practice'. Contributions which will be published under this heading are those short offerings which are not really technical methods as we know them, nor the contributions which we print as 'Letters to the Editor'. Technical methods, indeed, continue to be offered in profusion and they form an important section of the Journal. 'Letters to the Editor', introduced two years ago, are a means by which readers can comment upon something said in a previous issue, or perhaps offer a modification of a method.

We hope, later in 1971, to introduce the SI nomenclature, as was foreseen in our Editorial in December (J. clin. Path., 1970, 23, 743), and also in 1971 we are producing Reprint No. 2, the second in a series of detailed descriptions of techniques. We have had in the past such descriptions, notably that on electrophoresis, embodied in review articles. The way we have now chosen to present recommended major techniques, such as those used in vaginal cytology (Reprint No. 1), is in the more practical form of 'reprints'; extra copies for use at the bench can be purchased.

In the early days of the Journal the review articles were notable. We have not ceased to publish such review articles from time to time, but the flow of original contributions has become a deluge, and commissioned reviews are perhaps less frequently published. Nevertheless, the Editorial Board will keep in mind the necessity to review great topics in clinical pathology.

Side by side with the Journal have appeared under its banner the published proceedings of symposia held under the auspices of the Association of Clinical Pathologists jointly with the Association of Clinical Biochemists and, more recently, by the Royal College of Pathologists. We are happy that we can offer our readers such important supplements at such modest prices. 